\title{
One-pot multicomponent green Hantzsch synthesis of 1,2-dihydropyridine derivatives with antiproliferative activity
}

\author{
Giovanna Bosica ${ }^{*}$, Kaylie Demanuele ${ }^{1}$, José M. Padrón ${ }^{2}$ and Adrián Puerta ${ }^{2}$
}

\section{Full Research Paper}

Address:

${ }^{1}$ Department of Chemistry, University of Malta, Msida, MSD 2080 Malta and ${ }^{2}$ BioLab, Instituto Universitario de Bio-Orgánica "Antonio González" (IUBO-AG), Universidad de La Laguna, c/Astrofísico Francisco Sánchez 2, 38206 La Laguna, Spain

Email:

Giovanna Bosica* - giovanna.bosica@um.edu.mt

* Corresponding author

Keywords:

antiproliferative activity; 1,2-dihydropyridines; green Hantzsch synthesis; heterogeneous catalysis; one-pot multicomponent reaction
Beilstein J. Org. Chem. 2020, 16, 2862-2869.

https://doi.org/10.3762/bjoc. 16.235

Received: 29 August 2020

Accepted: 06 November 2020

Published: 24 November 2020

This article is part of the thematic issue "Green chemistry II". The article is dedicated to the memory of Prof. Bosica's mother, Mrs. Maria Nespoli.

Associate Editor: L. Vaccaro

(C) 2020 Bosica et al.; licensee Beilstein-Institut.

License and terms: see end of document.

\begin{abstract}
A rapid route for obtaining unsymmetrical 1,2-dihydropyridines (1,2-DHPs) as opposed to 1,4-dihydropyridines (1,4-DHPs) has been achieved via a one-pot multicomponent Hantzsch reaction. A benign protocol has been developed for the preparation of various 1,2-dihydropyridine derivatives using heterogenized phosphotungstic acid on alumina support (40 wt \%). High yields of over $75 \%$ have been accomplished in just 2-3.5 h after screening several heterogeneous catalysts and investigating the optimal reaction conditions. The catalyst chosen has passed the heterogeneity test and was shown to have the potential of being reused for up to 8 consecutive cycles before having a significant loss in activity. In addition, aromatic aldehydes gave the aforementioned regioisomer while the classical 1,4-DHPs were obtained when carrying out the reaction using aliphatic aldehydes. The preliminary study of the antiproliferative activity against human solid tumor cells demonstrated that 1,2-DHPs could inhibit cancer cell growth in the low micromolar range.
\end{abstract}

\section{Introduction}

A multicomponent approach towards the synthesis of the desired product offers a number of advantages over a stepwise method. Such advantages include the development of a design that is: cheaper, simpler, economical, and environmentally friendly $[1,2]$. Multicomponent reactions are not new to research. The pioneer multicomponent reactions are the Hantzsch (1882), Biginelli (1891), Mannich (1912), Passerini
(1921), and Ugi (1959) reactions [3]. The significance of such a phenomenal approach for the synthesis of novel compounds first began as a way of increasing the chemical libraries and then shifted to obtaining products that are in high demand on an industrial scale at a cheaper and more benign way [4]. Recently, negative human impacts have been greatly witnessed as a result of population growth, so environmentally friendly design has 
become one of the most important contributions. As a result, such research has grown exponentially in the past decade $[5,6]$.

The work conducted by the German chemist Arthur Hantzsch exploded in the synthetic interest in dihydropyridines and pyridines when the pharmacological usefulness of these compounds in medicine was discovered [7]. The structural resemblance of these compounds to the coenzyme reduced nicotinamide adenine dinucleotide (NADH) sparked the potential pharmaceutical properties, and till today, the Hantzsch synthesis is the main route for obtaining such products, which are eventually used as active pharmaceutical ingredients in the pharmaceutical industry $[3,8]$. An analysis of the market shows that there are over 7000 drugs derived from dihydropyridines, some of which are blockbuster drugs, such as Tamiflu ${ }^{\circledR}$, dioscorine, ibogaine, and isoquinuclidines $[9,10]$.

Classically the Hantzsch synthesis involved the condensation of 2 equivalents of the $\beta$-ketoester ethyl acetoacetate (2) with benzaldehyde (1a) and ammonia (Scheme 1) [11]. This procedure was later optimized over the years using different substrates by varying the $\beta$-ketoesters and aldehydes in order to prepare a larger array of 1,4-dihydropyridines (1,4-DHPs) [12] In addition, further developments were made to the methodology in order to enhance the reaction yield and also to reduce the reaction time. Other recent developments involve reducing the energy and waste that is produced in the reaction for a more environmentally friendly synthesis [13-16]. The source of nitrogen has also been varied from the classical use of ammonia. The most common nitrogen source reported in literature is ammonium acetate (3). Others include the use of oxahydrazines, prima- ry amines, and urea. The oxidation of dihydropyridines to pyridines has been achieved using mild oxidizing agents $[7,17,18]$.

One of the greatest limitations of this synthesis is however the fact that the dihydropyridines that are obtained are usually the 1,4-symmetrical ones. This multicomponent reaction has been thought to have one of the most complex mechanisms since various routes might take place, and the mechanism depends much on the identity of the substrates and the reaction conditions used [18]. Cao and collaborators have managed to synthesize the 1,2-dihydropyridine (1,2-DHP) regioisomer as the main product through the Hantzsch synthesis at room temperature and solvent-free conditions, irrespective of the electronic effect of the substituted benzaldehydes studied [19]. This was a further improvement of the reaction since the usual regioisomer has always been reported to be the 1,4-DHP. Cao et al. have suggested an alternative mechanism for this route. When the same reaction was conducted under argon, they obtained a mixture of the two regioisomers (1,4-DHP/1,2-DHP 32:68), proving further the complexity of this reaction [19].

Therefore, continuing our studies for the development and application of environmentally friendly methodologies for multicomponent reactions [20], we attempted to find a green catalyst that could provide a wide substrate scope for the Hantzsch synthesis of 1,2-dihydropyridines in a short reaction time.

In order to achieve a green method, apart from utilizing a multicomponent reaction as a route providing a high atom economy, heterogeneous catalysis should be used since it offers a greener

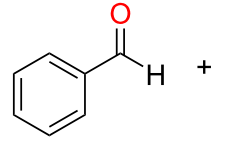

$1 \mathbf{a}$

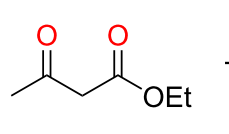

2
$\mathrm{NH}_{4} \mathrm{OAC}$

3

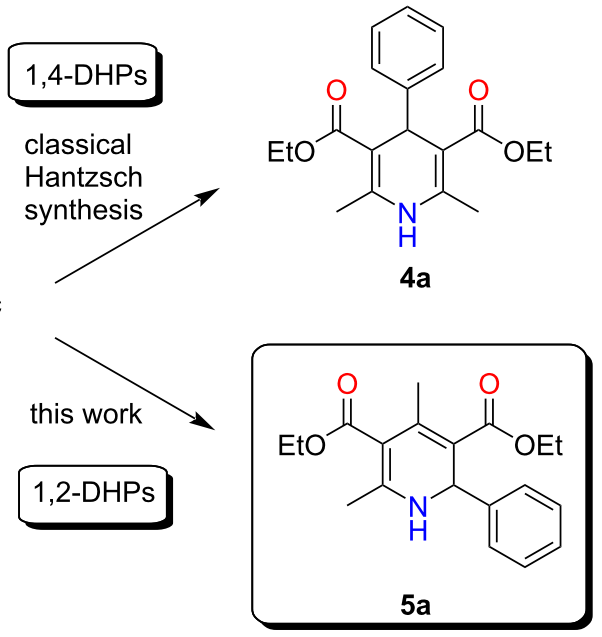

Scheme 1: The classical Hantzsch synthesis between benzaldehyde (1a), ethyl acetoacetate (2), and ammonium acetate (3) as well as the synthesis highlighted in this work. 
alternative to homogeneous catalysis and ideally a solvent-free design to reduce the amount of solvent waste $[21,22]$. These two factors will reduce the amount of hazardous chemicals by reducing the amount of solvent in the reactor and during the workup of the product. A solid insoluble catalyst can easily be removed from the reaction mixture via filtration, unlike a soluble one [23-25].

\section{Results and Discussion}

According to literature, the reaction has shown to work best and most efficiently under acidic conditions since such conditions enhance the selectivity. When the model reaction between benzaldehyde (1a), ethyl acetoacetate (2), and ammonium acetate $(3$, Scheme 1$)$ was carried out in the absence of any catalyst, it turned out to be very slow and, according to GC chromatograms, stopped in the early stages since the peaks of the corresponding starting materials of the model reaction appeared. A number of acidic catalysts was then analyzed before choosing the optimal catalyst (Table 1). The most significant result selected was based on the yield and reaction time.

The Nafion ${ }^{\circledR}$ catalysts showed the most promising results when carrying out the screenings. These catalysts were not further studied since they are no longer commercially available, and the preparation requires rather extreme conditions. The four catalysts chosen for further investigation according to the preliminary screenings shown in Table 1 were the activated resin Amberlyst ${ }^{\circledR} 15$ (Table 1, entry 6), 40 wt \% PW on silica
(Table 1, entry 9), a $30 \mathrm{wt} \% \mathrm{PW}$ loading on montmorillonite K30 clay (Table 1, entry 11), and a $40 \mathrm{wt} \%$ PW loading on alumina (Table 1, entry 12).

The study on the optimal reaction conditions shed a light on the acidity and the physical characteristics required for the reaction to be successful; the reaction requires strong acids. In addition, a peculiar result was obtained when analyzing the structure of the product obtained since the less frequently reported regioisomer, the unsymmetrical 1,2-DHP, was being obtained in a high yield and with a high selectivity. At this stage, further optimization and reaction trials were required in order to better understand the reaction conditions needed for the best results in terms of yield and selectivity of this transformation. The following investigation on each selected catalyst included changes in the molar ratio of the reagents, in the amount of catalyst, and in the temperature as well as the effect of the chosen green solvents (Figure 1).

Increasing the temperature did not significantly change the reaction yield or reduce the reaction time, while the presence of a green solvent, such as water or ethanol, negatively impacted the course of the reaction. Increasing the amount of catalyst did have a positive effect on the reaction, however, this was observed only up to a certain weight. The molar ratio of the reagents was altered by increasing the amount of ammonium acetate $(\mathbf{3})$ in the model reaction. This again had no particularly positive effect. Since the presence of water was shown to be

\begin{tabular}{|c|c|c|c|}
\hline entry ${ }^{a}$ & catalyst & yield $(\%)^{b}$ & reaction time $(\mathrm{h})$ \\
\hline 1 & Nafion ${ }^{\circledR}$ NR-50 & 88 & 5 \\
\hline 2 & Nafion ${ }^{\circledR}$ SAC-13 & 96 & 5 \\
\hline 3 & montmorillonite $\mathrm{K} 30$ & 72 & 4.5 \\
\hline 4 & Dowex $^{\circledR} 50 \mathrm{~W}$ & 48 & 5.5 \\
\hline 5 & Amberlyst ${ }^{\circledR} 15$ & 68 & 5.5 \\
\hline $6^{c}$ & activated Amberlyst ${ }^{\circledR} 15$ & 82 & 5 \\
\hline 7 & 40 wt \% silicotungtstic acid on cellulose & 49 & 6 \\
\hline 8 & 40 wt $\%$ silicotungstic acid $/ \mathrm{Al}_{2} \mathrm{O}_{3}$ & 37 & 6 \\
\hline 9 & 40 wt \% phosphotungstic acid $(\mathrm{PW}) / \mathrm{SiO}_{2}$ & 61 & 6 \\
\hline 10 & 20 wt \% silicotungstic acid/montmorillonite K10 & 40 & 6 \\
\hline $11^{\mathrm{d}}$ & 30 wt \% PW/montmorillonite K30 & 83 & 2.5 \\
\hline 12 & 40 wt $\% \mathrm{PW} / \mathrm{Al}_{2} \mathrm{O}_{3}$ & 94 & 3.5 \\
\hline 13 & 40 wt $\% \mathrm{PW} /$ acidic $\mathrm{Al}_{2} \mathrm{O}_{3}$ & 85 & 4 \\
\hline 14 & 30 wt \% PW/Amberlyst ${ }^{\circledR} 15$ & 80 & 4.5 \\
\hline 15 & 50 wt $\% \mathrm{H}_{3} \mathrm{PO}_{4} / \mathrm{Al}_{2} \mathrm{O}_{3}$ & 74 & 5 \\
\hline 16 & 30 wt \% phosphomolybdic acid/Amberlyst ${ }^{\circledR} 15$ & 43 & 6 \\
\hline
\end{tabular}

aReaction carried out under neat conditions using $0.04 \mathrm{~g} / \mathrm{mmol}$ of the catalyst and a 1a/2/3 1:2:1 ratio. ${ }^{\text {b }}$ Yield of the pure isolated product. ${ }^{\mathrm{C}}$ Activation by heating overnight at $100^{\circ} \mathrm{C}$. ${ }^{\mathrm{d}} \mathbf{1 a / 2 / 3}$ 1:2:2 ratio. 


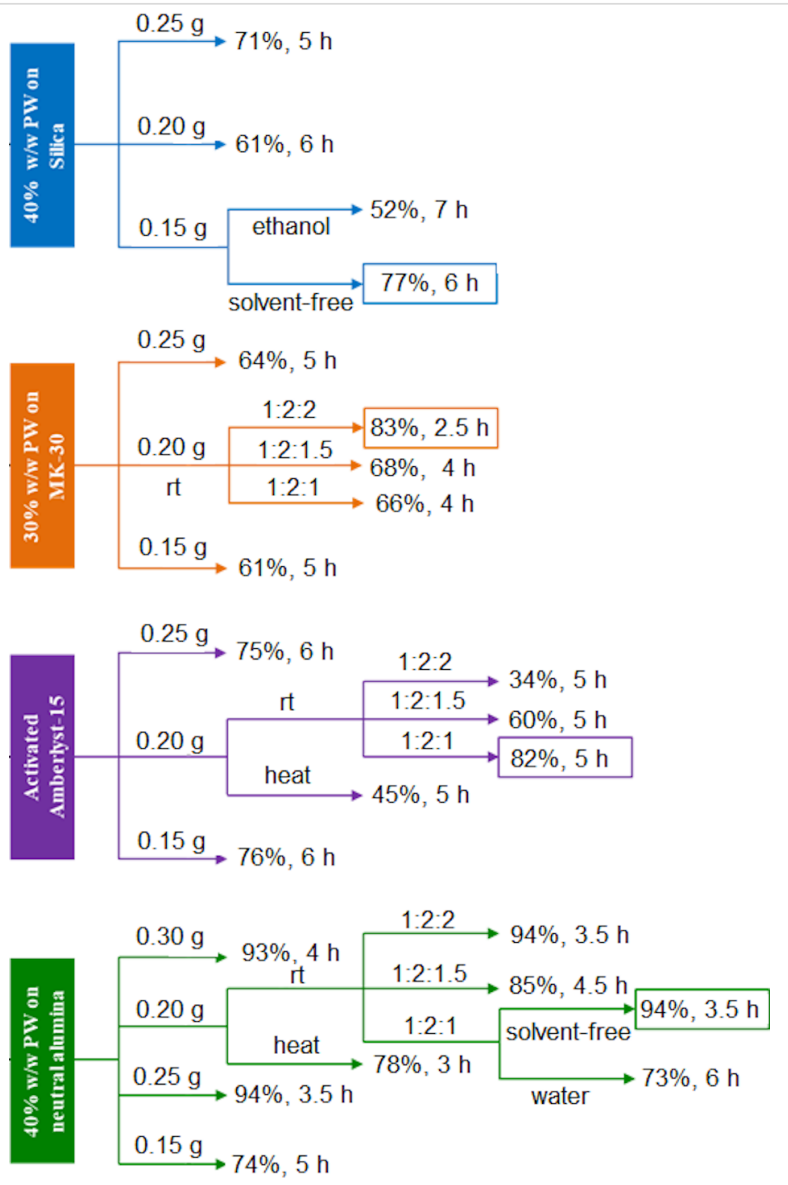

Figure 1: Optimization trials with the selected solid catalysts. detrimental, the ammonium acetate (3) used was left to dry in a desiccator before use.

Reaction monitoring was mostly done using thin-layer chromatography (TLC) and at times also GC. These techniques showed the occurrence of at least three intermediates before reaching the ultimate product. No side products were observed at the end of all reactions, which shed a light on the selectivity obtained using the developed protocol. The results from the optimization trials are highlighted in Figure 1.

The optimal reaction conditions chosen included room temperature, a stoichiometric molar ratio of the reactants, using $40 \mathrm{wt} \%$ PW loaded on alumina under solvent-free conditions. These conditions satisfied the green protocol we were aiming for. Therefore, from this stage we moved onto the next one by changing the substrates to explore the versatility of the developed method.

The selectivity was promising even for the other substrates used (Table 2). Various substituted benzaldehydes were used, and all gave similar results. Deviations from the model reaction occurred in terms of the expected reaction time and yield, but generally, the deviations from the model reaction were minimal.

Unexpectedly, when carrying out the reaction using aliphatic aldehydes under the same conditions, a different regioisomer, the commonly reported 1,4-DHP instead of the 1,2-DHP, was

Table 2: Screening of different substrates.

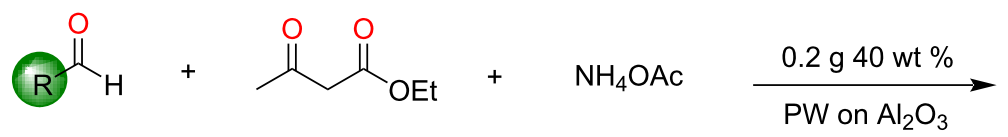

1

2<smiles>[2H][C@]1(C)NC(C)=C(C(=O)OCC)C(C)=C1C(=O)OCC</smiles>

5

\begin{tabular}{|c|c|c|c|}
\hline product $^{\mathrm{a}}$ & $\mathrm{R}$ & yield of $5(\%)^{b}$ & time $(\mathrm{h})$ \\
\hline $5 a$ & $\mathrm{C}_{6} \mathrm{H}_{5}(\mathbf{1 a})$ & 94 & 4.5 \\
\hline $5 b$ & $2-\mathrm{OH}-\mathrm{C}_{6} \mathrm{H}_{4}(\mathbf{1 b})$ & 73 & 3.5 \\
\hline $5 c$ & $2,4-(\mathrm{OH})_{2}-\mathrm{C}_{6} \mathrm{H}_{3}(\mathbf{1 c})$ & 96 & 4 \\
\hline $5 d$ & $2,4-\mathrm{Cl}_{2}-\mathrm{C}_{6} \mathrm{H}_{3}(\mathbf{1 d})$ & 65 & 6 \\
\hline $5 e$ & $3-\mathrm{CH}_{3} \mathrm{O}-\mathrm{C}_{6} \mathrm{H}_{4}(1 \mathrm{e})$ & 62 & 5 \\
\hline $5 f$ & $2-\mathrm{CH}_{3} \mathrm{O}-\mathrm{C}_{6} \mathrm{H}_{4}(\mathbf{1 f})$ & 62 & 5.5 \\
\hline $5 g$ & $4-\mathrm{CH}_{3}-\mathrm{C}_{6} \mathrm{H}_{4}(\mathbf{1 g})$ & 64 & 4.5 \\
\hline $5 h$ & $4-\mathrm{N}\left(\mathrm{CH}_{3}\right)_{2}-\mathrm{C}_{6} \mathrm{H}_{4}(\mathbf{1 h})$ & 92 & 4 \\
\hline $5 \mathbf{i}$ & naphthyl (1i) & 90 & 4 \\
\hline $5 \mathbf{j}$ & 2,3-(methylenedioxy)- $\mathrm{C}_{6} \mathrm{H}_{3}(\mathbf{1} \mathbf{j})$ & 81 & 4.5 \\
\hline
\end{tabular}

aThe reactions were performed on a $5 \mathrm{mmol}$ scale under neat conditions at room temperature and in the presence of $0.04 \mathrm{~g} / \mathrm{mmol} 40 \mathrm{wt} \% \mathrm{PW}$ on alumina at a molar ratio of $1: 2: 1$. bPure isolated product. 
produced in the form of $\mathbf{4}$ with a high selectivity (Table 3), which was also reported by Cao and collaborators [19].

\section{Catalyst characterization and recyclability}

The catalyst was analyzed by X-ray fluorescence (XRF) spectroscopy in order to ascertain the $\mathrm{PW} / \mathrm{Al}_{2} \mathrm{O}_{3}$-support ratio. The mass percentage ratio of tungsten, which is the main component of the catalyst, and aluminium, the major element of the support, was used to determine the percentage of PW in the ensemble. According to the data obtained by XRF spectroscopy, the PW loading of $38.4 \mathrm{wt} \%$ was concordant to the theoretical value of $40 \mathrm{wt} \%$.

When the reusability test was carried out with the model reaction using the optimal catalyst, $40 \mathrm{wt} \% \mathrm{PW}$ on alumina, a substantial yield loss of $13 \%$ was observed after the 8 th cycle while the required reaction time increased by 30 minutes after the 7 th cycle (Figure 2). This result confirmed the green character of the protocol, which is what we were aiming for.

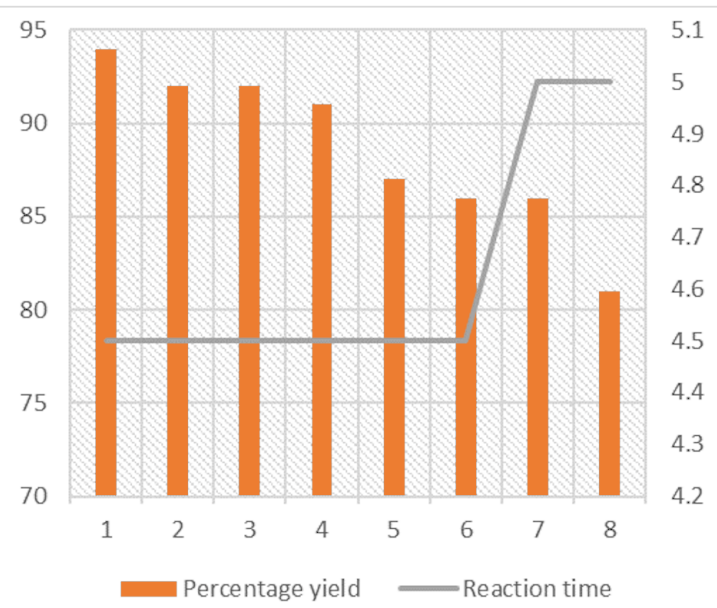

Figure 2: Graphical representation of the results obtained in the reusability test.

\section{Green metrics}

The green character of a reaction can be approximately quantified by calculating both the E-factor and the atom economy (AE), amongst other factors. The AE of the Hantzsch synthesis for the model reaction involving benzaldehyde (1a, $1 \mathrm{~mol})$, ethyl acetoacetate $(2,2 \mathrm{~mol})$ and ammonium acetate $(3,1 \mathrm{~mol})$ is equal to $74 \%$ :

$$
\begin{aligned}
\mathrm{AE} & =\frac{m(\text { product })}{m(\text { starting materials })} \\
& =\frac{329.39 \mathrm{~g}}{2 \cdot 130.14 \mathrm{~g}+106.12 \mathrm{~g}+77.08 \mathrm{~g}} \cdot 100 \%=74.3 \%
\end{aligned}
$$

In order to take the amount of waste generated by the materials that are not directly involved in the reaction into consideration, the E-factor was also calculated:

$$
\begin{aligned}
\mathrm{E} & =\frac{m \text { (product })+m \text { (catalyst })}{m(\text { catalyst })+m(\text { starting materials })} \\
& =\frac{1.548 \mathrm{~g}+0.2 \mathrm{~g}}{0.2 \mathrm{~g}+0.385 \mathrm{~g}+0.531 \mathrm{~g}+1.301 \mathrm{~g}}=0.72
\end{aligned}
$$

The mass used for the calculation is that of the starting materials of the model reaction and that of the catalyst used in the general procedure.

\section{Biological screening}

The 1,4-DHP scaffold displays an extensive range of biological activities, including reversing multidrug resistance (through the inhibition of the P-glycoprotein) [26] and antiproliferative effects on human cancer cell lines [27]. We wondered whether the studied 1,2-DHPs could interfere with tumor cell growth. Thus, we selected a small subset of 1,2-DHPs and screened them against a panel of six human solid tumor cell lines. The

Table 3: Results obtained when using the aliphatic aldehydes 1 in the Hantzsch synthesis.

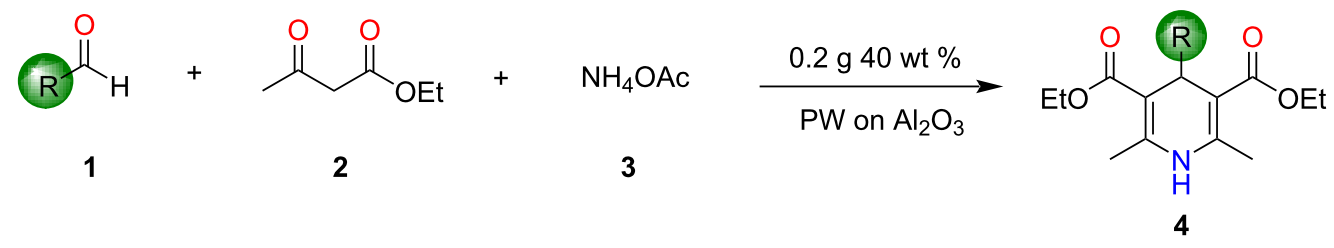

\begin{tabular}{llll}
\hline product $^{\mathrm{a}}$ & aldehyde & yield of $\mathbf{4}(\%)^{\mathrm{b}}$ & time (h) \\
\hline 4b & cyclohexanal (1k) & 82 & 4 \\
4c & penten-2-al (1) & 79 & 4 \\
\hline
\end{tabular}

aThe reactions were performed on a $5 \mathrm{mmol}$ scale under neat conditions at room temperature and in the presence of $0.04 \mathrm{~g} / \mathrm{mmol} 40 \mathrm{wt} \% \mathrm{PW}$ on alumina at a molar ratio of $1: 2: 1$. b Pure isolated product. 
results are shown in Table 4. Interestingly, the majority of the 1,2-DHPs displayed antiproliferative activity against all cell lines, in the low micromolar range. The most active compound was $5 \mathbf{e}$, which exhibited $\mathrm{GI}_{50}$ values in the range of 2.7-5.6 $\mu \mathrm{M}$. The results obtained are comparable to those of the standard anticancer drug cisplatin (CDDP), which was used as reference drug.

\section{Conclusion}

The one-pot multicomponent Hantzsch reaction for the synthesis of substituted dihydropyridines was performed under green heterogeneous and neat conditions in the presence of $0.04 \mathrm{~g} / \mathrm{mmol}$ of a $40 \mathrm{wt} \%$ phosphotungstic acid on alumina catalyst, which is simple, safe and environmentally benign to prepare, fully recoverable, and reusable for up to 8 runs. A high $\mathrm{AE}$ of $74 \%$ and a low E-factor of 0.72 highlight the green character of the procedure. More importantly, PW/alumina was able to catalyze a wide range of reactions involving different aromatic aldehydes to give products in good to excellent yields and interestingly all with the same general structure, corresponding to the 1,2-DHP regioisomer, unless when using aliphatic aldehydes.

\section{Experimental General}

All the chemicals used were purchased form Sigma-Aldrich. IR spectroscopy studies were conducted on a Shimadzu IRAffinity-1 FTIR spectrometer calibrated against $1602 \mathrm{~cm}^{-1}$ polystyrene absorbance spectra. The ${ }^{1} \mathrm{H}$ NMR and ${ }^{13} \mathrm{C}$ NMR spectra were measured on a Bruker Avance III HD ${ }^{\circledR}$ NMR spectrometer equipped with an Ascend 50011.75 Tesla superconducting magnet, operating at $500.13 \mathrm{MHz}$ for ${ }^{1} \mathrm{H}$ and 125.76 MHz for ${ }^{13} \mathrm{C}$, and a multinuclear $5 \mathrm{~mm}$ PABBO probe. Melting points were recorded on a Stuart ${ }^{\circledR}$ SMP11 melting point apparatus. Reactions were monitored by TLC and GC. Mass spectra were measured via a Thermo Scientific GC/MS DSQ II device, which contained a column: EC-5 $30 \mathrm{~m} \times$ $0.25 \mathrm{~mm}$ i.d. $\times 0.25 \mu \mathrm{m}$ or using the direct-infusion method using a Waters ${ }^{\circledR}$ ACQUITY $^{\circledR}$ TQD system with a tandem quadrupole mass spectrometer. The software used was ThermoXcalibur 2.2 SP1.48. The XRF spectroscopy analysis of the catalyst was performed using a Bruker S2 Ranger $^{\circledR}$.

\section{Catalyst preparation}

The method previously reported by Zhu et al. was used to prepare several supported heteropoly acids (silicotungstic and $\mathrm{PW}$ ) on various supports at different loadings [28]. For $1 \mathrm{~g}$ of a catalyst batch with a loading of $20 \mathrm{wt} \%, 0.8 \mathrm{~g}$ of the support and $0.2 \mathrm{~g}$ of a heteropoly acid were stirred in a minimum amount of distilled water to form a slurry for 8 hours at room temperature in a $10 \mathrm{~mL}$ round-bottomed flask. Then, the catalyst was dried overnight at $110^{\circ} \mathrm{C}$ and ultimately calcined at $250{ }^{\circ} \mathrm{C}$ in a furnace under air for $4 \mathrm{~h}$ to obtain a white powder $(1 \mathrm{~g})$, which was stored in a calcium chloride/silica-filled desiccator.

\section{General method}

The general method involved the addition of 1 equiv of the aldehyde (5 mmol), 2 equiv ethyl acetoacetate $(2,10 \mathrm{mmol})$, and 1 equiv ammonium acetate $(3,5 \mathrm{mmol})$ in one vessel. The reactants were left to stir together with $0.2 \mathrm{~g}$ of the catalyst (40 wt \% PW on alumina). At intervals of 30 minutes, the reaction mixture was analyzed using TLC, GC, or both. With time, the reaction mixture was observed to change from colorless to yellow, which darkened or brightened to orange or yellow and thickened with the occurrence of crystals on the sides of the flask. Once the spot or the peak corresponding to the benzaldehyde disappeared on the TLC plate or in the gas chromatogram,

\begin{tabular}{|c|c|c|c|c|c|c|}
\hline \multirow[t]{2}{*}{ compound } & \multicolumn{6}{|c|}{ cell line } \\
\hline & A549 & HBL-100 & HeLa & SW1573 & T-47D & WiDr \\
\hline $5 a$ & $29 \pm 4.6$ & $23 \pm 1.8$ & $21 \pm 2.0$ & $31 \pm 0.7$ & $21 \pm 2.5$ & $22 \pm 2.4$ \\
\hline $5 b$ & $>100$ & $>100$ & $28 \pm 7.5$ & $>100$ & $>100$ & $>100$ \\
\hline $5 d$ & $14 \pm 3.1$ & $19 \pm 3.0$ & $12 \pm 4.5$ & $22 \pm 1.2$ & $17 \pm 3.6$ & $17 \pm 1.2$ \\
\hline $5 e$ & $5.1 \pm 0.3$ & $4.8 \pm 0.4$ & $2.7 \pm 0.5$ & $5.6 \pm 1.0$ & $4.0 \pm 0.3$ & $3.3 \pm 0.5$ \\
\hline $5 f$ & $43 \pm 14$ & $42 \pm 6.2$ & $26 \pm 4.0$ & $49 \pm 12$ & $33 \pm 5.1$ & $41 \pm 9.6$ \\
\hline $5 g$ & $18 \pm 4.9$ & $20 \pm 0.9$ & $22 \pm 6.6$ & $18 \pm 6.8$ & $22 \pm 2.1$ & $18 \pm 1.6$ \\
\hline $5 h$ & $34 \pm 4.7$ & $38 \pm 4.0$ & $28 \pm 4.6$ & $33 \pm 6.1$ & $31 \pm 0.9$ & $39 \pm 8.9$ \\
\hline $5 i$ & $23 \pm 6.8$ & $26 \pm 2.0$ & $18 \pm 5.0$ & $30 \pm 0.3$ & $20 \pm 2.0$ & $33 \pm 4.8$ \\
\hline $5 j$ & $16 \pm 6.7$ & $16 \pm 3.5$ & $4.9 \pm 1.0$ & $11 \pm 1.7$ & $15 \pm 1.9$ & $19 \pm 3.3$ \\
\hline CDDP & $4.9 \pm 0.2$ & $1.9 \pm 0.2$ & $1.8 \pm 0.5$ & $2.7 \pm 0.4$ & $17 \pm 3.3$ & $23 \pm 4.3$ \\
\hline
\end{tabular}

${ }^{\mathrm{a}} \mathrm{Gl}_{50}$ values are given in $\mu \mathrm{M}$. The standard deviation was calculated from at least two independent experiments. CDDP (cisplatin) was used as a reference compound. Values in bold face represent the best antiproliferative data against tumor cell lines $\left(\mathrm{Gl}_{50}<10 \mu \mathrm{M}\right)$. 
the time was taken as the reaction was finished. The reaction mixture, obtained as a viscous oil, was filtered through a sinter funnel to remove any catalyst and washed using acetone, which was then evaporated in a rotary evaporator. The resultant crystals were then recrystallized using hot ethanol. The products were then characterized via IR, NMR, and MS analysis.

\section{Hot filtration test}

The optimized model reaction was monitored by GC, and the catalyst was left in the reaction mixture for 30 minutes in order to confirm heterogeneity. During these 30 minutes, the reaction started. However, upon removal of the catalyst by filtration, the reaction was left to carry on but stopped, and therefore catalyst leaching was not evident.

\section{Antiproliferative tests}

We selected the cancer cell lines A549 and SW1573 (nonsmallcell lung), HBL-100, as well as T-47D (breast), HeLa (cervix), and WiDr (colon) to evaluate the antiproliferative activity. The tests were performed in 96-well plates using the SRB assay [29] with the following specifications: the cell seeding density was 2500 cells/well for A549, HBL-100, HeLa, and SW1573, and 5000 cells/well for T-47D and WiDr. The drug incubation time was $48 \mathrm{~h}$. The optical density of each well was measured at 530 (primary) and $620 \mathrm{~nm}$ (secondary). The antiproliferative activity, expressed as $\mathrm{GI}_{50}$ values, was calculated according to the NCI formulas [30].

\section{Supporting Information}

\section{Supporting Information File 1 \\ Analytical data of the products. \\ [https://www.beilstein-journals.org/bjoc/content/ \\ supplementary/1860-5397-16-235-S1.pdf]}

\section{Acknowledgements}

The authors would like to thank Prof. Robert M. Borg for assistance with the acquisition of the NMR spectra and Mr. Godwin Sammut for MS analyses.

\section{Funding}

The authors thank the University of Malta and the ENDEAVOUR Scholarship Scheme (Malta), part-financed by the European Union-European Social Fund (ESF) under the Operational Programme II-Cohesion Policy 2014-2020, "Investing in human capital to create more opportunities and promote the well-being of society" for financial and technical support. A. P. and J. M. P. thank the Spanish Government for financial support through project PGC2018-094503-B-C22
(MCIU/AEI/FEDER, UE). A. P. thanks the EU Social Fund (FSE) and the Canary Islands ACIISI for a predoctoral grant TESIS2020010055.

\section{ORCID ${ }^{\circledR}$ iDs}

Giovanna Bosica - https://orcid.org/0000-0002-5674-870X José M. Padrón - https://orcid.org/0000-0001-6268-6552 Adrián Puerta - https://orcid.org/0000-0002-7975-1960

\section{References}

1. Dömling, A.; AIQahtani, A. D. General Introduction to MCRs: Past, Present, and Future. In Multicomponent Reactions in Organic Synthesis; Zhu, J.; Wang, Q.; Wang, M.-X., Eds.; Wiley-VCH: Weinheim, Germany, 2014; pp 1-12. doi:10.1002/9783527678174.ch01

2. Ganem, B. Acc. Chem. Res. 2009, 42, 463-472. doi:10.1021/ar800214s

3. Alvim, H. G. O.; da Silva Júnior, E. N.; Neto, B. A. D. RSC Adv. 2014, 4, 54282-54299. doi:10.1039/c4ra10651b

4. Touré, B. B.; Hall, D. G. Chem. Rev. 2009, 109, 4439-4486. doi:10.1021/cr800296p

5. Sheldon, R. A. Green Chem. 2017, 19, 18-43. doi:10.1039/c6gc02157c

6. Ciriminna, R.; Pagliaro, M. Org. Process Res. Dev. 2013, 17, 1479-1484. doi:10.1021/op400258a

7. Abdel-Mohsen, H. T.; Conrad, J.; Beifuss, U. Green Chem. 2012, 14 2686-2690. doi:10.1039/c2gc35950b

8. Ghorbani-Choghamarani, A.; Zolfigol, M. A.; Salehi, P.; Ghaemi, E.; Madrakian, E.; Nasr-Isfahani, H.; Shahamirian, M. Acta Chim. Slov. 2008, 55, 644-647.

9. Sharma, V. K.; Singh, S. K. RSC Adv. 2017, 7, 2682-2732. doi:10.1039/c6ra24823c

10. Javanbakht, S.; Shaabani, A. ACS Appl. Bio Mater. 2020, 3, 156-174. doi:10.1021/acsabm.9b00799

11. Lavilla, R. J. Chem. Soc., Perkin Trans. 1 2002, 1141-1156. doi:10.1039/b101371h

12. Silva, E. M. P.; Varandas, P. A. M. M.; Silva, A. M. S. Synthesis 2013, 45, 3053-3089. doi:10.1055/s-0033-1338537

13. Nasr-Esfahani, M.; Montazerozohori, M.; Raeatikia, R. Maejo Int. J. Sci. Technol. 2014, 8, 32-40.

14. Pal, S.; Choudhury, L. H.; Parvin, T. Synth. Commun. 2013, 43, 986-992. doi:10.1080/00397911.2011.618283

15. Pacheco, S. R.; Braga, T. C.; da Silva, D. L.; Horta, L. P.; Reis, F. S.; Ruiz, A. L. T. G.; de Carvalho, J. E.; Modolo, L. V.; de Fatima, A Med. Chem. 2013, 9, 889-896. doi:10.2174/1573406411309060014

16. Pramanik, A.; Saha, M.; Bhar, S. ISRN Org. Chem. 2012, 1-7. doi:10.5402/2012/342738

17. Vanden Eynde, J.; Mayence, A. Molecules 2003, 8, 381-391. doi:10.3390/80400381

18. D'Alessandro, O.; Sathicq, Á. G.; Sambeth, J. E.; Thomas, H. J.; Romanelli, G. P. Catal. Commun. 2015, 60, 65-69. doi:10.1016/j.catcom.2014.11.022

19. Shen, L.; Cao, S.; Wu, J.; Zhang, J.; Li, H.; Liu, N.; Qian, X. Green Chem. 2009, 11, 1414-1420. doi:10.1039/b906358g

20. Bosica, G.; Abdilla, R. Green Chem. 2017, 19, 5683-5690. doi:10.1039/c7gc02038d

21. Sheldon, R. A. Chem. Commun. 2008, 3352-3365. doi:10.1039/b803584a 
22. Cave, G. W. V.; Raston, C. L.; Scott, J. L. Chem. Commun. 2001, 2159-2169. doi:10.1039/b106677n

23. Heravi, M. M.; Bakhtiari, K.; Javadi, N. M.; Bamoharram, F. F.; Saeedi, M.; Oskooie, H. A. J. Mol. Catal. A: Chem. 2007, 264, 50-52. doi:10.1016/j.molcata.2006.09.004

24. Bitaraf, M.; Amoozadeh, A.; Otokesh, S. J. Chin. Chem. Soc. 2016, 63, 336-344. doi:10.1002/jccs.201500453

25. Liu, Y.; Zhao, G.; Wang, D.; Li, Y. Natl. Sci. Rev. 2015, 2, 150-166. doi:10.1093/nsr/nwv014

26. Firuzi, O.; Javidnia, K.; Mansourabadi, E.; Saso, L.; Mehdipour, A. R.; Miri, R. Arch. Pharmacal Res. 2013, 36, 1392-1402. doi:10.1007/s12272-013-0149-8

27. Sharma, M. G.; Vala, R. M.; Patel, D. M.; Lagunes, I.; Fernandes, M. X.; Padrón, J. M.; Ramkumar, V.; Gardas, R. L.; Patel, H. M. ChemistrySelect 2018, 3, 12163-12168. doi:10.1002/slct.201802537

28. Zhu, S.; Zhu, Y.; Gao, X.; Mo, T.; Zhu, Y.; Li, Y. Bioresour. Technol. 2013, 130, 45-51. doi:10.1016/j.biortech.2012.12.011

29. Orellana, E. A.; Kasinski, A. L. Bio-Protoc. 2016, 6, e1984. doi:10.21769/bioprotoc. 1984

30. Monks, A.; Scudiero, D.; Skehan, P.; Shoemaker, R.; Paull, K.; Vistica, D.; Hose, C.; Langley, J.; Cronise, P.; Vaigro-Wolff, A.; Gray-Goodrich, M.; Campbell, H.; Mayo, J.; Boyd, M.

J. Natl. Cancer Inst. 1991, 83, 757-766. doi:10.1093/jnci/83.11.757

\section{License and Terms}

This is an Open Access article under the terms of the Creative Commons Attribution License (https://creativecommons.org/licenses/by/4.0). Please note that the reuse, redistribution and reproduction in particular requires that the authors and source are credited.

The license is subject to the Beilstein Journal of Organic Chemistry terms and conditions:

(https://www.beilstein-journals.org/bjoc)

The definitive version of this article is the electronic one which can be found at:

https://doi.org/10.3762/bjoc.16.235 